\title{
Índice de criminalidade nas cidades do Rio Grande do Sul: hierarquização e dispersão espacial entre 2007 e 2014
}

\author{
Dary Ramos da Silva Neto \\ Victor Lima \\ Clailton Ataídes de Freitas ${ }^{3}$
}

\begin{abstract}
Resumo: O artigo tem o objetivo de construir um Índice de Criminalidade (IC) que contemple todas as cidades do estado do Rio Grande do Sul entre 2007 e 2014, por meio da ferramenta de Métodos Quantitativos de Estatística Multivariada, e aplicação da metodologia de Analise Fatorial (AF). Porto Alegre, Canoas e Caxias do Sul apresentaram os maiores índices de criminalidade do estado no período de 2007 e 2014. Além disso, o estudo revelou que, em geral, os maiores índices de criminalidade concentram-se nas cidades gaúchas pertencentes à região metropolitana de Porto Alegre e os menores índices, nas cidades interioranas.
\end{abstract}

Palavras-chave: Índice de criminalidade. Análise fatorial. Economia do crime.

Abstract: The objective of this article is to construct a Crime Index (CI) that covers all the cities of the state of Rio Grande from 2007 to 2014 through the tool of Quantitative Methods of Multivariate Statistics, applying a factorial analysis (FA) methodology. Porto Alegre, Canoas and Caxias do Sul had the highest levels of crime in the state during 2007 and 2014. In addition, the study revealed that, in general, the cities of Rio Grande do Sul that are part of the metropolitan region of Porto Alegre presented the highest rates of crime and the lowest rates.

Keywords: Crime rate. Factor analysis. Crime economic.

\section{Introdução}

A teoria do crime na literatura analisa a atividade criminal como uma atividade econômica, ou seja, tenta quantificar a abordagem dos recursos escassos e de que forma estes podem ser bem empregados por indivíduos, empresas e sociedade.

O estudo sobre economia social é recente e vem crescendo no país, deixando de lado o mainstream econômico, até então, principal foco de pesquisa, e também um reflexo das realidades enfrentadas nas economias de modo geral. Desigualdade, saúde, educação, pobreza, criminalidade são

\footnotetext{
${ }^{1}$ Pesquisador Assistente no Instituto de Pesquisa Econômica aplicada (IPEA) e mestrando no Programa de Pós-Graduação em Economia e Desenvolvimento pela Universidade Federal de Santa Maria (UFSM). E-mail: darcy.neto@ipea.gov.br.

2 Mestrando no Programa de Pós-Graduação em Economia e Desenvolvimento pela Universidade Federal de Santa Maria UFSM. E-mail: victorjrl@live.com.

${ }_{3}^{3}$ Doutor em Economia Aplicada pela Escola Superior de Agricultura Luiz de Queiroz da Universidade de São Paulo (ESALQ/USP) e Professor Titular do Departamento de Economia e Relações Internacionais DERI/UFSM. E-mail: lcv589@gmail.com.
}

Página 111 Caderno de Ciências Sociais Aplicadas, Vitória da Conquista/BA, vol. 15, n 26, ano 15, p. 111-131, jul/dez 2018. 
temas bastante relevantes e bem procurados para pesquisas na atualidade. No Brasil, os agravantes dos problemas sociais e o aumento da criminalidade vêm gerando curiosidade em estudiosos e pesquisadores. No entanto, esses problemas não podem ser tratados de forma individual e sem relação com outras áreas.

Desse modo, a intenção foi elaborar um trabalho que pudesse revelar o índice de criminalidade das cidades de um dos estados mais importantes do Brasil, o quinto mais populoso do país e com o quinto maior IDH: o Rio Grande do Sul (IBGE, 2018). O estudo teve também o propósito de verificar o nível de criminalidade das metrópoles e das cidades interioranas. Este trabalho é importante porque traz informações sobre a criminalidade das cidades gaúchas. Os dados podem auxiliar órgãos públicos no direcionamento de políticas que procurem amenizar os níveis de violência, contribuindo, portanto, para uma melhoria da qualidade de vida da população.

Inicialmente, o estudo versa sobre a teoria econômica do crime, contextualiza o modelo de Becker, em 1968, a abordagem e interpretações de outros autores. Os subitens desse primeiro capítulo estreitarão as análises do crime, as evidências empíricas para o mundo e, posteriormente, para o Brasil, estabelecendo a relação entre criminalidade e desigualdade social, pobreza, segurança, e outros itens dos fatores estruturais. Ao final do primeiro capítulo, passa-se para a contextualização da criminalidade no Estado do Rio Grande do Sul, objeto de análise em questão.

O capítulo subsequente versará sobre os aspectos metodológicos, as variáveis disponíveis, a base de dados a ser utilizada, bem como trará uma descrição detalhada do método de análise fatorial de estatística multivariada para a criação do índice de criminalidade proposto. O quarto capítulo apresentará análises e inferências das estatísticas e seus resultados, com uma subseção que mostrará os índices de criminalidade de forma hierárquica, em ordem decrescente (da cidade mais violenta para a menos violenta), e mapas com a dispersão espacial da criminalidade nas cidades gaúchas, além de análises que apontam possíveis modificações do índice em algumas cidades entre 2007 e 2014. Por fim, no capítulo referente às considerações finais, apresentam-se as principais conclusões, incluindo propostas de ampliação deste estudo, bem como as referências bibliográficas.

Página 112 Caderno de Ciências Sociais Aplicadas, Vitória da Conquista/BA, vol. 15, n 26, ano 15, p. 111-131, jul/dez 2018. 


\section{$2 \mathrm{O}$ modelo econômico do crime: a literatura internacional}

A teoria do crime começou a ser analisada por volta de 1960, com um modelo teórico desenvolvido por Gary Stanley Becker (1968) sociólogo e economista norte americano, professor da Universidade de Chicago. Ganhador do prêmio Nobel de 1992, Becker conseguiu estabelecer alguns princípios da denominada "economia do crime". De forma resumida:

O modelo teórico original se concentra nas relações comportamentais que explicariam os elevados gastos públicos e privados com a criminalidade. Essas relações são subdivididas em cinco categorias:

1. Entre números e custo social dos crimes;

2. Entre o número de crimes e a punição imposta;

3. Entre o número de crimes, prisões e condenações e o gasto público com polícia e judiciário;

4. Entre o número de condenações e o custo das penitenciárias e os outros tipos de punição;

5. Entre o número de crimes e o gasto privado com proteção e apreensão (BECKER, 1968).

A estrutura básica do que propõe Becker se resume em: função de oferta agregada dos crimes, os custos sociais da atividade criminosa, os custos de prender e condenar, punições e condição de otimização.

Matematicamente, há um comparativo entre as utilidades esperadas e as atividades de caráter legal e ilegal. Ou seja, o indivíduo $i$ optará pelo crime em vez do mercado de trabalho formal quando:

$(1-p r)^{*} U\left(l_{I}-c_{i}-M_{i}^{*}\right)-p r^{*} U(p u)>U\left(w_{i}\right)$

Onde $l_{i}$, ou loot, é o valor monetário recebido pelo crime cometido, $c_{i}$ é o custo de planejamento e execução, $M_{i}$ é atribuído a um tipo de custo moral, pré a probabilidade de ser pego e condenado, pu é o valor atribuído ao "castigo" de ser pego e $w_{i}$ é o custo de oportunidade comparando entre estar no mercado formal ou na criminalidade.

No modelo apresentado, salienta-se, existe uma tendência de o indivíduo reincidir após ter cometido algum crime. Essa visão deve ser incorporada no modelo simplificado apresentado, pois a experiência na atividade criminosa leva a uma redução nos custos, o "learning by doing", à diminuição nos

Página 113 Caderno de Ciências Sociais Aplicadas, Vitória da Conquista/BA, vol. 15, n 26, ano 15, p. 111-131, jul/dez 2018. 
custos morais e à perda de capital humano, pois o ingresso no mercado de trabalho formal de um excriminoso será mais difícil.

Para Araújo Jr. e Fajnzylber (2001), existem, pelo menos, duas implicações na reincidência: a condenação deveria afetar a incidência de tais atividades criminosas não só no que se refere ao indivíduo preso, mas também ao chamado efeito "incapacitação", ou seja, haveria menos crimes na rua porque os criminosos foram presos e foram retirados de circulação para cometer outros crimes. Porém, tais criminosos serão substituídos por outros indivíduos que se sentirão atraídos pelo retorno líquido (maior) dessa atividade, se a curva de oferta de crimes tiver inclinação positiva e deslocada para a esquerda no momento em que se "reduziu" o número de criminosos na rua e aumentou o "retorno" de cometer o ato ilícito.

A segunda implicação a que se referem os autores é a possível existência de taxas de inércia do crime. Em um dado momento do tempo, a criminalidade aumenta mesmo que outros fatores estejam constantes e, como consequência disso, haverá choques temporários que ampliam a criminalidade e com persistência a efeitos de curto e longo prazos. Quando um indivíduo ingressa na atividade criminal, a probabilidade de ele continuar no ramo ou de cometer algum ato delinquente em momento posterior é maior do que se estiver fora da criminalidade.

Para Carvalho et al. (2007), a criminalidade está associada a fatores estruturais, em termos de desorganização social. Status econômico, desagregação familiar, urbanização, renda, são fatores ligados diretamente ao crime. A teoria da anomia tenta explicar e justificar a motivação dos criminosos para atingir o modelo ideal de vida. São aspectos que explicam a conjuntural, portanto, o ambiente micro e macroestrutural dado por educação, renda, desemprego, pobreza, cultura, acesso e políticas públicas de combate à violência etc.

Conforme declararam Hagan e Peterson (1995), além dos fatores econômicos do modelo, há questões sociológicas que podem ser incorporadas à variável "custo moral". A privação relativa ou a sensação de frustração de um indivíduo diante da sociedade, a prosperidade de outros ao seu redor geram um confronto. Isso pode explicar os efeitos da desigualdade sobre o crime que, nesse caso, está diretamente ligado às questões de pobreza. Além disso, a pobreza pode debilitar os mecanismos informais do comportamento individual. Em outras palavras, da desorganização social resulta o aumento de crime.

Página 114 Caderno de Ciências Sociais Aplicadas, Vitória da Conquista/BA, vol. 15, n² 26, ano 15, p. 111-131, jul/dez 2018. 
Além dos fatores econômicos e sociais, tratados anteriormente como causas da criminalidade, o modelo econômico do crime pode também apresentar uma explicação favorável. A entrada na "indústria do crime", que ocorre entre a adolescência e a vida adulta, pode resultar na possibilidade de emprego e salário no mercado de trabalho legal. Então, o ciclo de vida da participação criminal está ligado às variáveis do modelo econômico, ou seja, é possível argumentar que a elasticidade do comportamento criminal do indivíduo está relacionada com a sua idade, em que a função utilidade de cometer um crime varia de acordo com a faixa etária dos indivíduos (ARAÚJO JR. \& FAJNZYLBER, 2001).

\section{Metodologia}

A criminalidade pode ser definida por um conjunto de variáveis altamente complexas e diversificadas. Lançar mão de um grupo dessas variáveis e traçar um índice para representar a real situação de criminalidade dos municípios do Estado em questão constitui, por conseguinte, um desafio.

A metodologia de análise multivariada precisa, inicialmente, investigar a confiabilidade, que se caracteriza como o grau em que uma escala produz resultados consistentes entre medidas repetidas ou equivalentes de um mesmo objeto, relevando-se a ausência do erro (CORRAR; PAULO; DIAS FILHO, 2007). Trata-se da análise das escalas de mensuração, as quais permitem determinar a extensão em que os itens estão relacionados com os demais e a confiabilidade dos dados. Portanto, conforme Corrar, Paulo e Dias Filho (2007), um modelo bastante utilizado é o Alfa de Cronbach ( $\alpha$ ), que trata da consistência interna baseada na correlação média entre os itens. De acordo com Hair et al. (2006), a ideia principal da medida de consistência interna é que os indicadores individuais da escala devem medir o mesmo constructo, sendo altamente correlacionados. O Alfa de Cronbach pode ser calculado pela seguinte fórmula:

$\alpha=\frac{k\left(\frac{\operatorname{cov}}{\operatorname{var}}\right)}{1+(k-1)\left(\frac{\operatorname{cov}}{\operatorname{var}}\right)}$

$\mathrm{k}=$ número de variáveis

cov $=$ média das covariâncias

var $=$ média das variâncias

Página 115 Caderno de Ciências Sociais Aplicadas, Vitória da Conquista/BA, vol. 15, n 26, ano 15, p. 111-131, jul/dez 2018. 
O valor assumido para $\alpha$ está entre 0 e 1 e, quanto mais próximo de 1 , maior a confiabilidade das dimensões do constructo. Hair et al. (2006) considera 0,7 um mínimo aceitável para pesquisas aplicadas.

A técnica de determinação fatorial surgiu com o trabalho de Charles Spearman, em 1904, para descrever a inteligência mediante um único fator. Spearman (1904) desenvolveu um método para a criação de um índice geral de inteligência (fator "g"), com base nos resultados de vários testes que avaliavam essa aptidão. No entanto, coube a Thurstone (1931) o surgimento do termo análise fatorial.

O método da análise fatorial é uma técnica estatística multivariada cujo objetivo é transformar um número relativamente grande de variáveis em um número reduzido em cargas fatoriais que possam explicar as variáveis originais (MANLY, 1986).

Segundo Corrar, Paulo e Dias Filho (2007), o método da Análise de Componentes Principais procura uma combinação linear entre as variáveis, de forma que o máximo da variância seja explicado. No modelo seguinte, cada variável $\mathrm{X}_{i}$ observada representa uma combinação linear dos n componentes principais. Então, cada uma das i-ésimas variáveis é uma combinação de $k(k<i)$ fatores comuns e de um fator específico. O modelo genérico de análise fatorial pode ser representado da seguinte forma, considerando que cada variável tem uma relação linear com k fatores comuns (F), um fator único (U) e um termo aleatório:

$X_{i}=A_{i 1} F_{1}+A_{i 2} F_{2}+\cdots A_{i k} F_{k}+U_{i}+\varepsilon_{i}$

Em que $\mathrm{X}_{i}$ são as variáveis originais;

$\mathrm{A}_{i k}$ as cargas fatoriais usadas para combinar linearmente com os fatores comuns (F);

$\mathrm{F}_{k}$ são os fatores comuns;

$\mathrm{U}_{i} \mathrm{o}$ fator único;

$\mathrm{E}_{i}$ é o termo de erro que capta as variações de $\mathrm{X}_{\mathrm{i}}$.

As cargas fatoriais $\mathrm{A}_{i k}$ indicam intensidade das relações entre as variáveis normalizadas $\mathrm{X}_{i}$ e os fatores. Quanto maior uma carga fatorial, mais associada ao fator está a variável. O quadrado das cargas fatoriais representa a contribuição relativa de cada fator para a variância total da variável. A raiz característica expressa a variância total do modelo explicada por fator. Seu valor é o somatório dos quadrados das cargas fatoriais de cada variável associada ao fator específico. A raiz característica dividida pelo número de variáveis $\mathrm{X}_{i}$ determina a proporção da variância total explicada pelo fator.

Página 116 Caderno de Ciências Sociais Aplicadas, Vitória da Conquista/BA, vol. 15, n² 26, ano 15, p. 111-131, jul/dez 2018. 
Conforme Hoffmann (1999), a técnica Varimax é uma das mais usadas nos estudos de análise fatorial, visto que envolve a transformação ortogonal. Segundo Mingoti (2005), essa técnica produz soluções mais práticas que as outras (Quatimax e Orthomax). Esse método de rotação será, portanto, utilizado no presente estudo. Após calcular as cargas e identificar os fatores, estimam-se os escores fatoriais - variável importante para a elaboração do IC.

O escore de cada observação está na equação genérica:

$F_{j}=W_{j 1} X_{1}+W_{j 2} X_{2}+\cdots W_{j n} X_{n}$

Em que n é o número das variáveis;

$\mathrm{W}_{j n}$ são os coeficientes dos escores fatoriais.

De acordo com Monteiro e Pinheiro (2004), quanto mais distante de zero for o escore fatorial de uma observação, em valores positivos, melhor será a posição relativa da observação em um fator. Portanto, o desempenho dos estados em cada fator é determinado pelos valores comparativos da coluna correspondente ao fator na matriz de escores. Por fim, cabe analisar a qualidade do ajuste do modelo de análise fatorial. Para tanto, foram utilizadas duas medidas para examinar as intercorrelações entre as variáveis.

A estatística de Kaiser-Meyer-Olkin (KMO) é um indicador que compara a magnitude do coeficiente de correlação observado com a magnitude do coeficiente de correlação parcial. Considerando que os valores deste variam de 0 a 1, valores para $\mathrm{KMO}$ menores do que 0,5 indicam a não adequabilidade da análise. Valores entre 0,5 e 0,6 indicam uma adequabilidade ruim do modelo; entre 0,6 e 0,7, regular; entre 0,7 e 0,8, bom; entre 0,8 e 0,9, ótimo; e entre 0,9 e 1,0, excelente (HAIR et al., 2006).

\subsection{Descrição das variáveis, modelo e fonte dos dados}

A criminalidade pode ser definida por um conjunto de variáveis altamente complexas e diversificadas, sendo então um desafio lançar mão de um grupo dessas variáveis e traçar um índice capaz de representar a real situação de criminalidade dos municípios do Estado em questão. Com base nos dados fornecidos pela Secretaria de Segurança Pública do Estado do Rio Grande do Sul (2017),

Página 117 Caderno de Ciências Sociais Aplicadas, Vitória da Conquista/BA, vol. 15, n 26, ano 15, p. 111-131, jul/dez 2018. 
consideraram-se treze tipos de crimes cometidos e relatados em todos os municípios, no período compreendido entre 2007 e 2014:

Quadro 1 - Tipos de crime, descrição e referências

\begin{tabular}{|c|c|c|}
\hline Tipo de crime & Descrição & Referência \\
\hline Homicídio doloso $\left(\mathrm{V}_{1}\right)$ & $\begin{array}{l}\text { Ocorre quando uma pessoa mata outra ou tem a } \\
\text { intenção de matar. Previsto no artigo } 121, \text { p.1-2 do } \\
\text { Código Penal brasileiro. }\end{array}$ & \multirow{12}{*}{$\begin{array}{l}\text { Secretaria de Segurança Pública } \\
\text { do Rio Grande do Sul (2017) }\end{array}$} \\
\hline Furto $\left(V_{2}\right)$ & $\begin{array}{l}\text { Subtrair, para si ou para outrem, coisa alheia. } \\
\text { Previsto no artigo } 155 \text { do Código Penal brasileiro. }\end{array}$ & \\
\hline Furto de veículos $\left(V_{3}\right)$ & $\begin{array}{l}\text { Enquadra-se na categoria de subtração para si ou } \\
\text { para outrem, porém especificamente de veículos. }\end{array}$ & \\
\hline Roubos $\left(V_{4}\right)$ & $\begin{array}{l}\text { Ato de subtrair coisa móvel alheia para si ou para } \\
\text { outrem, mediante grave ameaça ou violência e, } \\
\text { depois de havê-la, por qualquer meio, reduz a } \\
\text { impossibilidade de resistência. Previsto no artigo } \\
157 \text { do Código Penal brasileiro. }\end{array}$ & \\
\hline Latrocínio $\left(\mathrm{V}_{5}\right)$ & $\begin{array}{l}\text { Mata-se para roubar. O crime de roubo é o crime- } \\
\text { fim e o crime de homicídio é o crime-meio. } \\
\text { Previsto no artigo } 157 \text { do Código Penal brasileiro. }\end{array}$ & \\
\hline Roubos de veículos $\left(\mathrm{V}_{6}\right)$ & $\begin{array}{l}\text { Ato de subtrair coisa móvel alheia para si ou para } \\
\text { outrem, mediante grave ameaça ou violência e, } \\
\text { depois de havê-la, por qualquer meio, reduz a } \\
\text { impossibilidade de resistência. Entretanto, exclusivo } \\
\text { para veículos. }\end{array}$ & \\
\hline Extorsão $\left(V_{7}\right)$ & $\begin{array}{l}\text { É o ato de obrigar alguém a tomar um determinado } \\
\text { comportamento, por meio de ameaça ou violência, } \\
\text { para obter vantagem ou lucro. Previsto no artigo } \\
158 \text { do código penal brasileiro. }\end{array}$ & \\
\hline $\begin{array}{l}\text { Extorsão mediante sequestro } \\
\qquad\left(\mathrm{V}_{8}\right)\end{array}$ & $\begin{array}{l}\text { Sequestrar alguém com o fim de obter lucro ou } \\
\text { vantagem. Previsto no artigo } 159 \text { do código penal } \\
\text { brasileiro. }\end{array}$ & \\
\hline Estelionato $\left(\mathrm{V}_{9}\right)$ & $\begin{array}{l}\text { Crime contra o patrimônio para obter vantagem } \\
\text { ilícita, em prejuízo alheio, para qualquer tipo de } \\
\text { meio fraudulento. Previsto no artigo } 171 \text { do código } \\
\text { penal brasileiro. }\end{array}$ & \\
\hline $\begin{array}{l}\text { Delitos relacionados à } \\
\text { corrupção }\left(\mathrm{V}_{10}\right)\end{array}$ & $\begin{array}{l}\text { Ato ou feito de se corromper, oferecer algo para } \\
\text { obter vantagem em negociata que se favorece uma } \\
\text { pessoa e prejudica outra. Previsto no artigo } 333 \text { do } \\
\text { código penal brasileiro. }\end{array}$ & \\
\hline $\begin{array}{c}\text { Delitos relacionados a armas e } \\
\text { munições }\left(\mathrm{V}_{11}\right)\end{array}$ & $\begin{array}{l}\text { A lei } \mathrm{n}^{\circ} 10.826 / 2003 \text { dispõe dos crimes } \\
\text { relacionados a armas de fogo e munições. Previsto } \\
\text { no código penal brasileiro nos artigos } 13 \text { ao } 21 .\end{array}$ & \\
\hline Entorpecentes (posse) $\left(V_{12}\right)$ & $\begin{array}{l}\text { Adquirir, guardar, transportar ou tiver consigo para } \\
\text { consumo pessoal drogas sem autorização e }\end{array}$ & \\
\hline
\end{tabular}

Página 118 Caderno de Ciências Sociais Aplicadas, Vitória da Conquista/BA, vol. 15, n² 26, ano 15, p. 111-131, jul/dez 2018. 


\begin{tabular}{|l|l|l|}
\hline \multirow{2}{*}{ Entorpecentes (tráfico) $\left(\mathrm{V}_{13}\right)$} & $\begin{array}{l}\text { desacordo com determinação legal. Previsto no } \\
\text { artigo 28 do código penal brasileiro. }\end{array}$ \\
\hline & $\begin{array}{l}\text { Qualquer tipo de movimentação e disposição de } \\
\text { drogas de um para outro em desacordo com } \\
\text { determinação legal. Previsto no artigo 33 do código } \\
\text { penal brasileiro. }\end{array}$ \\
\hline
\end{tabular}

Fonte: Elaborado pelos autores com base nos dados extraídos da Secretaria de Segurança Pública do RS.

Com base nessas variáveis, é possível formar os grupos que determinarão os indicadores da criminalidade (baixa, média e alta), com a aplicação dos mesmos critérios utilizados para medir o IDH (baixo, médio e alto). O método da análise fatorial constitui uma técnica estatística multivariada, cujo objetivo é transformar um número relativamente grande de variáveis em um número reduzido de cargas fatoriais que possam explicar as variáveis originais (MANLY, 1986).

\subsection{Método de cálculo de Índice de Criminalidade}

O índice de Criminalidade (IC) será calculado com base na soma dos escores fatoriais multiplicados pelos autovalores dos fatores comuns ortogonais. De posse dos escores fatoriais, é possível realizar o cálculo do Índice Bruto de Criminalidade (IBC) e, consequentemente, o Índice de Criminalidade (IC). A primeira equação mostra o cálculo do índice bruto:

$I B C i=\sum_{i=1}^{p} Y i . F i$

Onde:

$\mathrm{IBC}_{\mathrm{i}}$ é o índice bruto de criminalidade da $i$-ésima cidade;

p é o número de fatores utilizados na análise;

$Y_{i}$ são os escores dos componentes principais dos autovalores;

$F_{\mathrm{i}}$ são os autovalores de cada componente.

Obtido o Índice Bruto de Criminalidade (IBC), é possível calcular o Índice de Criminalidade (IC) para que os valores fiquem entre zero e um, com base na equação abaixo:

$I C=\frac{\left(I B C i-I B C^{\min }\right)}{\left.I B C^{\max }-I B C^{\min }\right)}$

Onde:

Página 119 Caderno de Ciências Sociais Aplicadas, Vitória da Conquista/BA, vol. 15, n 26, ano 15, p. 111-131, jul/dez 2018. 
IC é o Índice de Criminalidade;

IBC $i$ é o Índice Bruto de Criminalidade da $i$-ésima cidade analisada;

$\mathrm{IBC}^{\min }$ são os valores mínimos obtidos para o IBC $i$ da $i$-ésima cidade;

$\mathrm{IBC}^{\max }$ são os valores máximos obtidos para o IBC $i$ da $i$-ésima cidade.

O IC corresponde a um índice normalizado do IBC para as 496 cidades analisadas. Com o valor da equação do IC obtém-se uma padronização, após isso, far-se-á uma hierarquização das cidades, em ordem crescente de valores.

\section{Análise e inferências das estatísticas e discussão dos resultados}

Nesta seção serão apresentados os testes feitos com as bases de dados do período entre 2007 e 2014. O primeiro teste mostra a consistência interna dos dados, a estatística Alfa de Cronbach. A tabela 1 irá apresentar os resultados da estatística ao longo desses oito anos:

Tabela 1 - Teste do alfa de Cronbach ${ }^{4}$

\begin{tabular}{cc}
\hline Ano & Estatística alfa de Cronbach \\
\hline 2007 & 0,7283 \\
\hline 2008 & 0,7284 \\
\hline 2009 & 0,7536 \\
\hline 2010 & 0,7442 \\
\hline 2011 & 0,7383 \\
\hline 2012 & 0,7516 \\
\hline 2013 & 0,7538 \\
\hline 2014 & 0,7545
\end{tabular}

Fonte: Elaborado pelos autores com base nos dados extraídos da Secretaria de Segurança Pública do RS.

Como pode ser analisado na tabela 1, conforme Corrar, Paulo e Dias Filho (2007), o teste Alfa de Cronbach $(\alpha)$, trata da consistência interna baseada na correlação média entre os itens. Para a base de dados ser considerada bem ajustada, é necessário verificar valores acima de 0,7. Portanto, os dados utilizados gozam de confiabilidade, visto que não houve muita variação na comparação dos valores do teste aplicado aos anos em questão. No que tange à aplicação da análise fatorial pelo método dos

\footnotetext{
${ }_{4}^{4}$ Os anos de 2015 e 2016 foram incluídos na análise uma vez, porém, ambos apresentaram estatística alfa de Cronbach menor que 0,5. Diante disso, para ajustar o trabalho e garantir a confiabilidade dos dados, na análise, manteve-se apenas o período compreendido entre 2007 e 2014.
}

Página 120 Caderno de Ciências Sociais Aplicadas, Vitória da Conquista/BA, vol. 15, n² 26, ano 15, p. 111-131, jul/dez 2018. 
componentes principais, não existe na literatura uma regra quanto à determinação do número de fatores que devem ser utilizados. Usualmente, consideram-se prováveis valores acima da unidade, porém, as bases de dados utilizadas apresentam apenas um fator que explica mais de $80 \%$ da variância, como pode ser visto no quadro 2 :

Quadro 2 - Fatores, raiz característica, variância explicada e estatística KMO

\begin{tabular}{|c|c|c|c|c|}
\hline Ano & Fatores & Raiz característica & Variância explicada (\%) & Estatística KMO \\
\hline & & & & \\
\hline & & & & \\
\hline 2007 & F1 & 11,5055 & 88,50 & 0,9280 \\
\hline 2008 & F1 & 11,6699 & 89,77 & 0,9351 \\
\hline 2009 & F1 & 11,6114 & 89,32 & 0,9164 \\
\hline 2010 & F1 & 10,9612 & 84,32 & 0,9040 \\
\hline 2011 & F1 & 11,1439 & 85,72 & 0,9190 \\
\hline 2012 & F1 & 10,5701 & 81,31 & 0,9110 \\
\hline 2013 & F1 & 11,0261 & 84,82 & 0,9322 \\
\hline 2014 & F1 & 11,5388 & 88,76 & 0,9196 \\
\hline
\end{tabular}

Fonte: Elaborado pelos autores com base nos dados extraídos da Secretaria de Segurança Pública do RS.

A estatística Kaiser-Meyer-Olkin (KMO) avalia a adequabilidade da análise fatorial, ou seja, se a base de dados é apropriada para esse tipo de metodologia. Hair, Anderson \& Tatham (1987) mostram que os valores aceitáveis para uso do método precisam estar entre 0,5 e 1, alegando que KMO inferiores a 0,5 indicam uma análise fatorial inadequada e inaceitável. Na opinião de Kaiser \& Rice (1977), para uma melhor adequação do modelo à análise fatorial, os valores de KMO devem estar acima de 0,8. Independentemente dessa divergência entre os autores, a análise aqui especificada possui valores acima de 0,9 para todos os anos em questão, sendo adequado, portanto, o uso da análise fatorial.

A próxima tabela irá fazer a mesma análise, porém, para 2014, último ano do estudo. É possível perceber que a carga fatorial da variável V7 aumentou em relação a 2007, sendo de 0,2404 com uma comunalidade de $57,8 \%$.

Página 121 Caderno de Ciências Sociais Aplicadas, Vitória da Conquista/BA, vol. 15, n 26, ano 15, p. 111-131, jul/dez 2018. 


\section{Cadernos de Ciéncias SOCIAIS APLICADAS}

Tabela 2 - Cargas fatoriais e comunalidades (2014)

\begin{tabular}{ccc}
\hline Variável & F1 & Comunalidade \\
\hline V1 & 0.2879 & 0.829 \\
\hline V2 & 0.2829 & 0.800 \\
\hline V3 & 0.2816 & 0.793 \\
\hline V4 & 0.2894 & 0.838 \\
\hline V5 & 0.2907 & 0.845 \\
\hline V6 & 0.2859 & 0.817 \\
\hline V7 & 0.2404 & 0.578 \\
\hline V8 & 0.2825 & 0.798 \\
\hline V9 & 0.2892 & 0.836 \\
\hline V10 & 0.2890 & 0.835 \\
\hline V11 & 0.2271 & 0.516 \\
\hline V12 & 0.2654 & 0.704 \\
\hline V13 & 0.2847 & 0.811
\end{tabular}

Fonte: Elaborado pelos autores com base nos dados extraídos da Secretaria de Segurança Pública do RS.

Para o ano de 2014, a variável com maior carga e, consequentemente, maior comunalidade, passou a ser V5, respectivamente, com 0,2907 e 84,5\%. Nesse caso, é possível notar que todas as variáveis possuem uma correlação praticamente na mesma proporção do fator encontrado, mesmo V7 sendo ainda a mais fraca, houve um aumento no comparativo entre 2007 e 2014. A variável V7, referente a crime de extorsão, é a que possui uma correlação com menor intensidade na abrangência dos crimes ocorridos e relatados dentro do estado.

O ponto principal dessa parte da análise é poder verificar que as 13 variáveis conseguiram ser agrupadas em apenas um único fator, com variância explicada acima de 80\%. Ou seja, com apenas uma raiz característica foi possível agrupar 13 variáveis sobre a criminalidade no estado do Rio Grande do Sul ao longo de oito anos. Essa informação tem capacidade de explicar mais de $80 \%$ da análise. A importância dos trabalhos empíricos é justamente conseguir retratar a realidade com dados relevantes e confiáveis.

A subseção seguinte irá discriminar o resultado da construção do índice ao longo do período analisado, retratando dois momentos, os anos de 2007 e 2014. A partir disso, serão feitas as considerações principais sobre a evolução desses índices no ranking das cidades. 


\subsection{O Índice de Criminalidade no estado do Rio Grande do Sul ${ }^{5}$}

A Tabela 3 revela o Índice de Criminalidade de cada cidade do estado do Rio Grande do Sul em 2007. Com base no Índice Bruto de Criminalidade (IBC), houve uma padronização dos valores entre zero e um. A tabela abaixo mostra os índices na ordem de hierarquização das cidades, ou seja, da cidade com maior índice de violência para a menor. ${ }^{6}$

Tabela 3 - Índice de criminalidade dos municípios classificados em ordem crescente $(2007)^{7}$

\begin{tabular}{|c|c|c|}
\hline Classificação & Municípios & Índice de Criminalidade \\
\hline 1 & Porto Alegre & 7.17648 \\
\hline 2 & Canoas & 1.00000 \\
\hline 3 & Caxias do Sul & 0.98117 \\
\hline 4 & Novo Hamburgo & 0.92263 \\
\hline 5 & Pelotas & 0.75548 \\
\hline 6 & São Leopoldo & 0.73461 \\
\hline 7 & Santa Maria & 0.59902 \\
\hline 8 & Viamão & 0.56255 \\
\hline 9 & Gravataí & 0.56010 \\
\hline 10 & Passo Fundo & 0.55555 \\
\hline 11 & Alvorada & 0.46838 \\
\hline 12 & Uruguaiana & 0.45356 \\
\hline 13 & Rio Grande & 0.39285 \\
\hline 14 & Santa Cruz do Sul & 0.36854 \\
\hline 15 & Cachoeirinha & 0.31724 \\
\hline 16 & Sapucaia do Sul & 0.27288 \\
\hline 17 & Cruz Alta & 0.25895 \\
\hline 18 & Erechim & 0.20189 \\
\hline 19 & São Borja & 0.19965 \\
\hline 20 & Santo Ângelo & 0.19268 \\
\hline 21 & Tramandaí & 0.18978 \\
\hline 22 & Bento Gonçalves & 0.18560 \\
\hline 23 & Lajeado & 0.18414 \\
\hline 24 & Taquara & 0.18077 \\
\hline 25 & Vacaria & 0.17488 \\
\hline 26 & Torres & 0.17306 \\
\hline
\end{tabular}

\footnotetext{
${ }^{5}$ Por uma questão de espaço, foram considerados apenas dois momentos da análise, 2007 e 2014. Porém, fez-se o estudo de todos os anos entre um período e outro e verificou-se que não houve maiores discrepâncias.

${ }^{6}$ Porto Alegre aparece com valores acima de 1 porque foi tirada do cálculo da padronização do índice por discrepar muito das outras. Contudo, a capital possui um indicador de violência 7,17 vezes maior que Canoas, considerada a cidade mais violenta do Estado, com valor 1 no ano de 2007.

${ }^{7}$ Por uma questão de tamanho, estão sendo apresentados os valores das 49 cidades mais violentas, as que entram no ranking de alta e média criminalidade. Da cidade número 50 até a última, a de número 496, todas se incluem na faixa de baixo Índice de Criminalidade no ano de 2007.
}

Página 123 Caderno de Ciências Sociais Aplicadas, Vitória da Conquista/BA, vol. 15, n² 26, ano 15, p. 111-131, jul/dez 2018. 


\section{- Cadernos de CiêncIas SOCIAIS APLICADAS}

\begin{tabular}{lll}
\hline 27 & Esteio & 0.17192 \\
\hline 28 & Sapiranga & 0.16889 \\
\hline 29 & Bagé & 0.15511 \\
\hline 30 & Cachoeira do Sul & 0.15477 \\
\hline 31 & Ijuí & 0.15453 \\
\hline 32 & Guaíba & 0.15367 \\
\hline 33 & Camaquã & 0.15169 \\
\hline 34 & Encruzilhada do Sul & 0.14746 \\
\hline 35 & Capão da Canoa & 0.14731 \\
\hline 36 & Alegrete & 0.14158 \\
\hline 37 & Carazinho & 0.13846 \\
\hline 38 & Santana do Livramento & 0.13544 \\
\hline 39 & Montenegro & 0.11588 \\
\hline 40 & Soledade & 0.11507 \\
\hline 41 & Charqueadas & 0.11504 \\
\hline 42 & Igrejinha & 0.11278 \\
\hline 43 & Campo Bom & 0.11236 \\
\hline 44 & São Luiz Gonzaga & 0.10778 \\
\hline 45 & Venâncio Aires & 0.10380 \\
\hline 46 & Garibaldi & 0.10336 \\
\hline 47 & Sobradinho & 0.10201 \\
\hline 48 & Dom Pedrito & 0.10171 \\
\hline 49 & Santiago & 0.10053 \\
\hline
\end{tabular}

Fonte: Elaborado pelos autores com base nos dados extraídos da Secretaria de Segurança Pública do RS.

A análise mostra que, em 2007, a maior parte das cidades possui índice menor que 0,1. Canoas, que está na posição 2 e só perde para a capital, e Santiago atingiram os índices 1,00 e 0,10053, respectivamente. Conforme especificado na metodologia, as cidades terão três níveis de criminalidade: alto, médio e baixo. Porto Alegre e Santiago, com as respectivas posições 1 e 49, são consideradas cidades com alto e médio índices de criminalidade. Tal informação está de acordo com o que estabelece o referencial teórico apresentado, segundo o qual cidades maiores são mais propícias ao crime devido à dificuldade de reconhecimento e retenção do criminoso, baixo custo de "entrada na atividade", renda per capita, entre outros fatores abordados.

À exceção da capital, Canoas está no topo do ranking das mais violentas. Alguns motivos podem justificar essa liderança: De acordo com o IBGE (2005), o município sedia grandes empresas nacionais e multinacionais, possui o segundo maior PIB gaúcho, além de ser o mais populoso da região metropolitana, com um total de 329.174 habitantes, em 2005. No quesito educação, a cidade também se destaca, visto que concentra escolas públicas e particulares e três universidades, a segunda maior rede de ensino do estado. Esses sinais de prosperidade compõem, no entanto, uma divergência da própria

Página 124 Caderno de Ciências Sociais Aplicadas, Vitória da Conquista/BA, vol. 15, n 26, ano 15, p. 111-131, jul/dez 2018. 
teoria do crime: cidades em situações extremas (com elevados ou baixos índices de educação e renda) possuem níveis de criminalidade altos. Os pesquisadores da área de economia do crime habitualmente deparam-se com essas antíteses, as quais podem ser um tanto particulares, a depender da área de estudo.

De acordo com o IBGE (2010), a dez maiores cidades do estado em tamanho populacional são: Porto Alegre, Caxias do Sul, Pelotas, Canoas, Santa Maria, Gravataí, Viamão, Novo Hamburgo, São Leopoldo e Rio Grande. Vê-se, portanto, que a criminalidade tem uma forte relação com o tamanho da cidade, ficando excluída do "top 10" da criminalidade Rio Grande, a 10a maior cidade do estado, com um índice de criminalidade de 0,39285 , em 2007, e a $13^{\text {a }}$ no ranking, dando lugar a Passo Fundo, a $10^{\mathrm{a}}$ mais violenta e a $12^{\mathrm{a}}$ em tamanho.

Todos os municípios com índices que vão de 1,00, em ordem decrescente, até 0,500 , foram considerados de alto índice de criminalidade. Esse conjunto abrange 10 cidades do estado, em 2007, conforme a tabela 3. Passo Fundo ocupa a posição 10 no ranking, com um índice de 0,55555. As posições de 11 a 49 ajustam-se na segunda classificação, que são as cidades com "índice de criminalidade médio". A cidade de posição número 11 é Alvorada, com 0,46838, e a posição 49 é Santiago, com 0,10053. Da posição 50, Balneário Pinhal, até a última, 496, Aceguá ${ }^{8}$, os índices são menores, vão de 0,100 até 0 . Tais cidades entram na terceira classificação, "baixo índice de criminalidade". A dispersão do índice de criminalidade, em 2007, está descrita no mapa a seguir:

\footnotetext{
${ }^{8}$ Isso significa que em termos relativos a cidade de Aceguá possui o menor índice de criminalidade, mas não está isenta de crimes.
}

Página 125 Caderno de Ciências Sociais Aplicadas, Vitória da Conquista/BA, vol. 15, n 26, ano 15, p. 111-131, jul/dez 2018. 


\section{Cadernos de CiênCIAS SOCIAIS APLICADAS}

Mapa 1 - Dispersão espacial da criminalidade (2007)

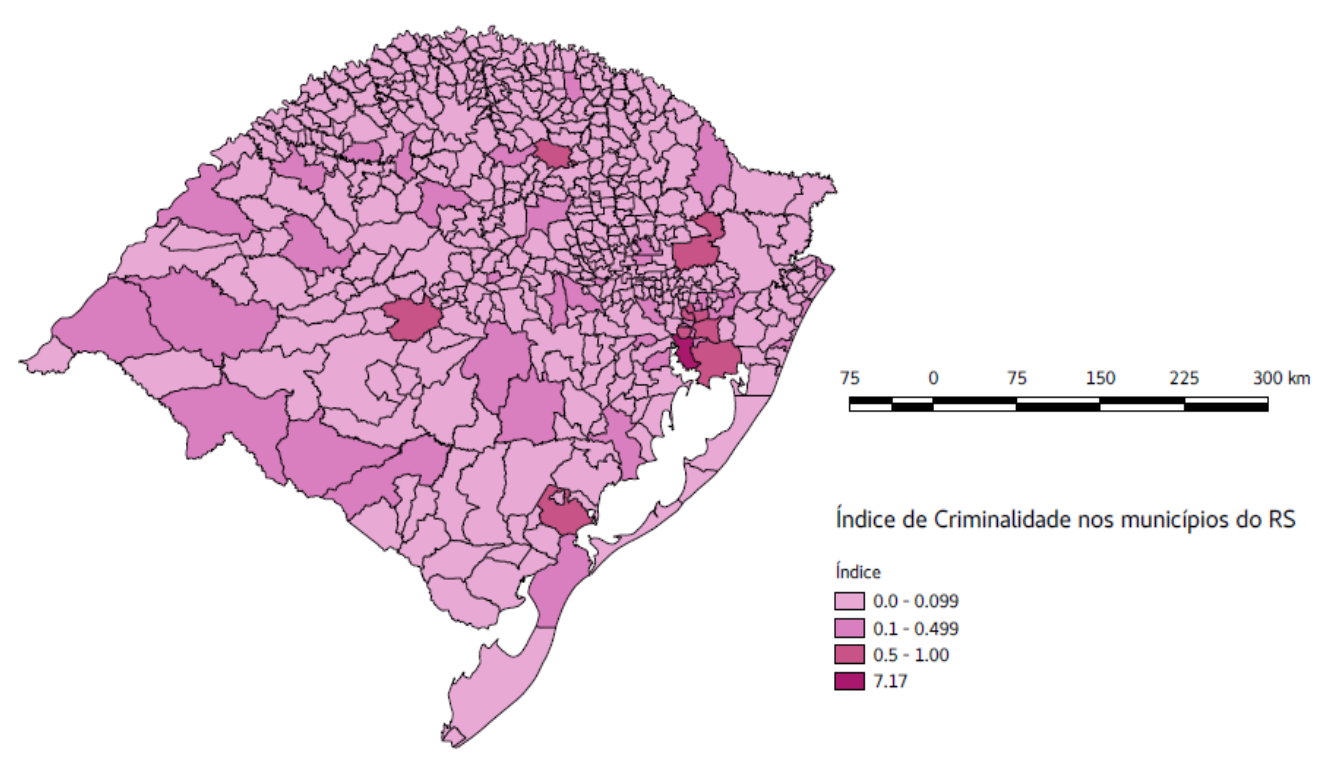

Fonte: Elaborado pelos autores com base nos dados gerados pelo software livre QGis 2.18.13.

O mapa 1 mostra os dados sobre a criminalidade no estado de acordo com as categorias de crimes. É possível observar também que, em 2007, a criminalidade concentrava-se na região metropolitana de Porto Alegre e se espalhava pelo estado, de modo que municípios na faixa de fronteira com Uruguai e Argentina atingiram índices médios de criminalidade. Os índices de Porto Alegre são analisados separadamente, devido à discrepância no número de crimes em comparação com as outras cidades. Ela fez parte do estudo apenas para fornecer parâmetros que permitam comparar o grande número de crimes ocorridos na capital em relação às cidades com índices inferiores. Conforme a tabela 3, Porto Alegre é 7,17 vezes mais violenta que Canoas (com 1,00), a segunda cidade mais violenta do Estado.

Agora, serão feitas as principais análises da dinâmica do ranking de todas as cidades em 2014, de acordo com a tabela 4. É possível perceber modificações no "top 10" das cidades com maiores índices de criminalidade. Depois de oito anos, mantêm-se nas três primeiras posições: Porto Alegre, Canoas e Caxias do Sul. São Leopoldo, no entanto, subiu da $6^{a}$ posição, em 2007, para a 4ª em 2014; Viamão, da $8^{a}$ posição para a $7^{a}$, Gravataí, da $9^{a}$ para a $5^{a}$.

Outras cidades caíram de posição no ranking: Pelotas, da $5^{\mathrm{a}}$ para a $8^{\mathrm{a}}$; Novo Hamburgo, da $4^{\mathrm{a}}$ para a $6^{\text {a }}$; Santa Maria, do $7^{\circ}$ lugar para o $10^{\circ}$. Passo Fundo saiu do "top $10^{\prime}$ " para a $12^{a}$ posição, em 2014. Uruguaiana foi uma das cidades com a maior evolução nos indicadores, caindo da $12^{a}$ posição em

Página 126 Caderno de Ciências Sociais Aplicadas, Vitória da Conquista/BA, vol. 15, n² 26, ano 15, p. 111-131, jul/dez 2018. 
2007 para a $23^{\mathrm{a}} \mathrm{em} 2014$. Isso pode ser tanto um reflexo da eficácia de políticas públicas no combate à criminalidade quanto pelo fato de essa cidade fazer fronteira com a Argentina, condição que requer um reforço, principalmente contra o crime de tráfico de entorpecentes.

Tabela 4 - Índice de criminalidade dos municípios classificados em ordem crescente (2014)9

\begin{tabular}{|c|c|c|}
\hline Classificação & Municípios & Índice de criminalidade \\
\hline 1 & Porto Alegre & 5.08262 \\
\hline 2 & Canoas & 1.00000 \\
\hline 3 & Caxias do Sul & 0.97504 \\
\hline 4 & São Leopoldo & 0.86330 \\
\hline 5 & Gravataí & 0.83274 \\
\hline 6 & Novo Hamburgo & 0.79205 \\
\hline 7 & Viamão & 0.67078 \\
\hline 8 & Pelotas & 0.64322 \\
\hline 9 & Alvorada & 0.58215 \\
\hline 10 & Santa Maria & 0.55038 \\
\hline 11 & Rio Grande & 0.51736 \\
\hline 12 & Passo Fundo & 0.40005 \\
\hline 13 & Sapucaia do Sul & 0.37452 \\
\hline 14 & Cachoeirinha & 0.33634 \\
\hline 15 & Santa Cruz do Sul & 0.28138 \\
\hline 16 & Bento Gonçalves & 0.28100 \\
\hline 17 & Esteio & 0.25029 \\
\hline 18 & Campo Bom & 0.23319 \\
\hline 19 & Charqueadas & 0.22966 \\
\hline 20 & Lajeado & 0.22536 \\
\hline 21 & Tramandaí & 0.22153 \\
\hline 22 & Erechim & 0.21596 \\
\hline 23 & Uruguaiana & 0.20683 \\
\hline 24 & Montenegro & 0.20676 \\
\hline 25 & Alegrete & 0.19050 \\
\hline 26 & Sapiranga & 0.18753 \\
\hline 27 & Guaíba & 0.18583 \\
\hline 28 & Taquara & 0.17462 \\
\hline 29 & Venâncio Aires & 0.17254 \\
\hline 30 & Farroupilha & 0.16553 \\
\hline 31 & Torres & 0.15856 \\
\hline 32 & Vacaria & 0.15223 \\
\hline 33 & Ijuí & 0.15146 \\
\hline 34 & Bagé & 0.14056 \\
\hline 35 & Osório & 0.13906 \\
\hline 36 & Cruz Alta & 0.12973 \\
\hline
\end{tabular}

${ }^{9}$ A mesma análise do ano de 2007 foi utilizada para 2014. Porto Alegre aparece com valores acima de 1 porque foi excluída do cálculo da padronização do índice por discrepar muito das outras. Contudo, essa cidade possui um indicador de violência 5,08 vezes maior que Canoas, a cidade mais violenta do Estado, com valor 1, em 2014.

Página 127 Caderno de Ciências Sociais Aplicadas, Vitória da Conquista/BA, vol. 15, n 26, ano 15, p. 111-131, jul/dez 2018. 


\section{- Cadernos de CiêncIas SOCIAIS APLICADAS}

\begin{tabular}{lll}
\hline 37 & Capão da Canoa & 0.12722 \\
\hline 38 & Carazinho & 0.12443 \\
\hline 39 & São Borja & 0.11154 \\
\hline 40 & Santo Ângelo & 0.11106 \\
\hline 41 & Triunfo & 0.11087 \\
\hline 42 & Estância Velha & 0.10847 \\
\hline 43 & Cachoeira do Sul & 0.10765 \\
\hline 45 & Marau & 0.10683 \\
\hline 46 & Camaquã & 0.10530 \\
\hline
\end{tabular}

Fonte: Elaborado pelos autores com base nos dados extraídos da Secretaria de Segurança Pública do RS.

Em 2014, o indicador das cidades com "alto índice de criminalidade" subiu de 10 para 11. Rio Grande ocupa a $11^{a}$ posição, com um índice de 0,51736. De Passo Fundo, que ocupa a $12^{a}$ posição, com um índice de 0,40005, até Parobé, na 46 posição, todas as cidades englobam o indicador "índice de criminalidade médio". O mapa 2 apresenta a dispersão da criminalidade de acordo com o índice:

Mapa 2 - Dispersão espacial da criminalidade (2014)

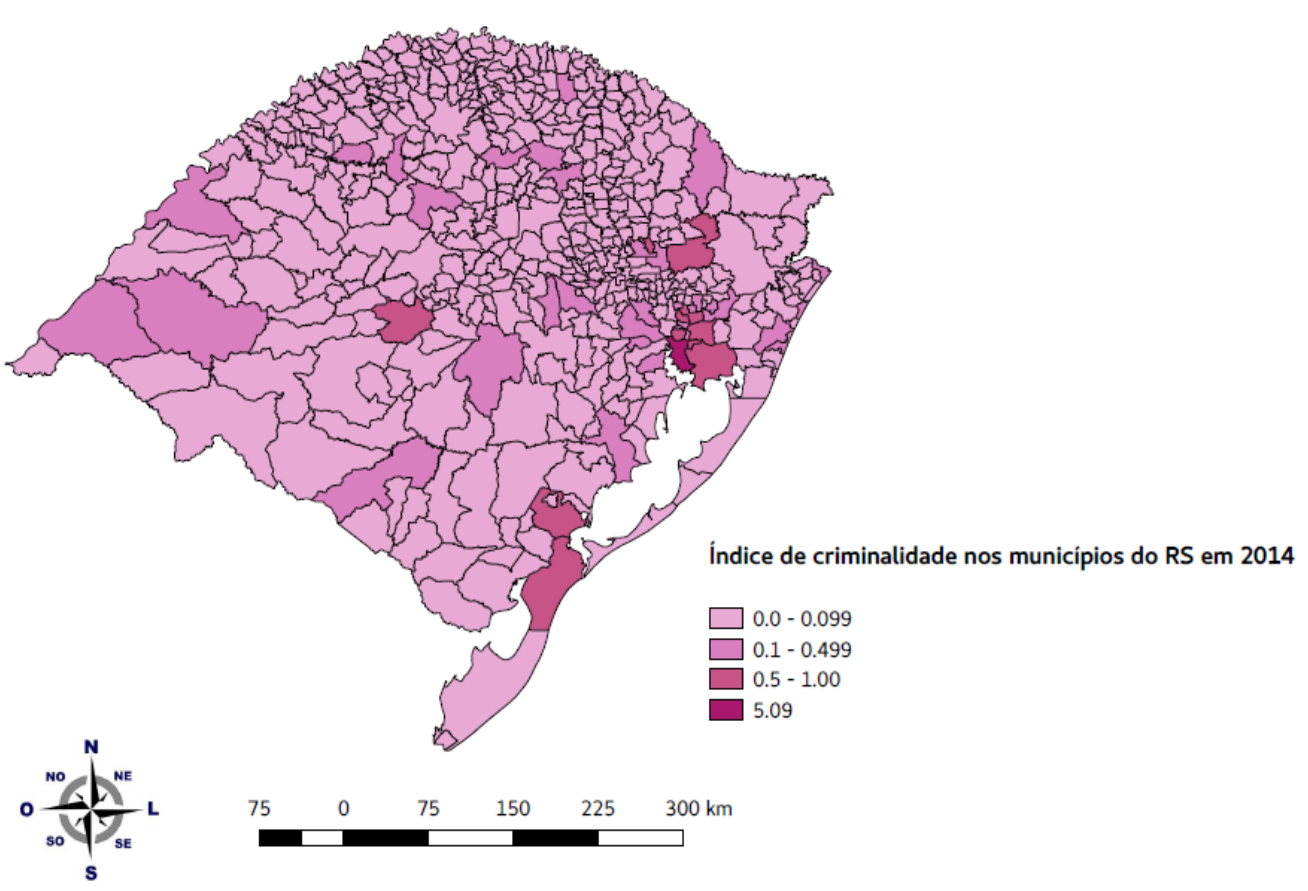

Fonte: Elaborado pelos autores com base nos dados gerados pelo software livre QGis 2.18.13.

No mapa 2 verifica-se também uma concentração da criminalidade na região metropolitana de Porto Alegre. Porém, comparados os anos 2007 e 2014, houve um aumento no número de cidades com baixo índice de criminalidade, o que é considerado benéfico para o estado.

Página 128 Caderno de Ciências Sociais Aplicadas, Vitória da Conquista/BA, vol. 15, n 26, ano 15, p. 111-131, jul/dez 2018. 
Dentro dos treze tipos de crime pesquisados, o maior número de registros coube a Porto Alegre. Ao longo destes oito anos, no entanto, a cidade conseguiu diminuir o índice de criminalidade, caiu de 7,17 para 5,08 vezes mais violenta que Canoas, a segunda colocada no ranking. Da mesma forma que se analisou o ano de 2007, verificou-se que, em 2014, as cidades entre a $47^{\mathrm{a}}$ (Soledade, com 0,09834 pontos) até a última posição (Novo Xingu, 496a) possuem um baixo índice de criminalidade, com valores entre 0 e 0,0999 .

\section{Considerações finais}

A proposta inicial deste trabalho foi abranger uma medida relativizada no que tange aos índices de criminalidade do estado do Rio Grande do Sul no decorrer de oito anos, de 2007 a 2014. Ao utilizar a metodologia de análise fatorial de componentes principais, foi possível construir um índice de criminalidade e hierarquizar as cidades, de acordo com a maior e a menor incidência de crimes.

A escolha da metodologia utilizada ajusta-se à análise proposta porque incorpora as variáveis aos diversos tipos de crimes analisados. Estabelece-se, por conseguinte, uma relação entre a teoria de Becker (1968) e os condicionantes do crime e seus desdobramentos: privação de educação, pobreza acentuada e desigualdade social e de renda, regiões com grande aglomeração populacional. Os resultados comprovam que existe um maior índice de criminalidade nas regiões mais desenvolvidas econômica e socialmente.

Este estudo compõe uma ideia inicial com a pretensão de ampliar-se para tratar da criminalidade nos níveis regional e nacional, bem como incorporar variáveis específicas, como estupro, nível de vulnerabilidade social, pobreza e extrema pobreza. Outro avanço seria analisar e avaliar a instituição das políticas municipais no combate à criminalidade e à violência.

\section{Referências}

ARAÚJO JR., A.F.; FAJNZYLBER, P. O Que Causa a Criminalidade Violenta no Brasil? Uma Análise a Partir do Modelo Econômico do Crime: 1981 A 1996. Texto de Discussão no.162, CEDEPLAR/UFMG, setembro de 2001.

ATLAS DA VIOLÊNCIA. Instituto de Pesquisa Econômica Aplicada - IPEA. Rio de Janeiro, 2017.

Página 129 Caderno de Ciências Sociais Aplicadas, Vitória da Conquista/BA, vol. 15, n 26, ano 15, p. 111-131, jul/dez 2018. 
BECKER, G. S. Crime e Punishment: An Economic Approach. Journal of Political Economy 76: 169217, 1968.

Nobel Lecture: The Economic Way of Looking at Behavior. Journal of Political Economy 101, 385-409, 1993.

CARVALHO, A. X., et al. Custos das mortes por causas externas no Brasil. Texto de discussão, 1268. Brasília, IPEA, 2007.

CASAGRANDE et. al. Proposição e cálculo do Índice de Desenvolvimento Educacional (IDE) para os Estados Brasileiros: uma aplicação da análise fatorial de 2007 a 2011. Ensaios FEE, Porto Alegre, v. 37, n. 1, p. 145-186, jun. 2016.

CORRAR, L. J.; PAUlO, E.; DIAS FILHO, J. M. (Org.). Análise Multivariada para os Cursos de Administração, Ciências Contábeis e Economia. São Paulo: Atlas, 2007.

FORUM BRASILEIRO DE SEGURANÇA PÚBLICA. Anuário Brasileiro de Segurança Pública 2016. Ano 10.São Paulo, 2016.

HAGAN, J.; PETERSON, R. D. Crime and Inequality. Stanford University Press, 1995.

HAIR, J. F.; ANDERSON, R. E.; TATHAM, R. L. Multivariate data analysis with readings. $2^{\text {nd }}$ ed. New York, Macmillan Publishing Company, p.449, 1987.

HAIR, J. F. et al. Multivariate data analysis. Upper Saddle River, NJ: Pearson Prentice Hall, 2006. HOFFMANN, R. Componentes Principais e Análise Fatorial. Piracicaba: Escola Superior de Agricultura Luiz de Queiroz, 1999.

IBGE. Instituto Brasileiro de Geografia e Estatística. Censo demográfico, 2010.

Instituto Brasileiro de Geografia e Estatística. Panorama. Disponível em: < https://cidades.ibge.gov.br/brasil/rs/panorama>. Acesso em: 10 de setembro de 2018.

KAISER, H. F.; RICE, J. Little Jiffy, Mark IV. Educational and Psychological Measurement, 34, 111 $-117,1977$.

MANLY, B. F. J. Multivariate statistical methods-a primer. New York: Chapman and Hall, 1986. MINGOTI, S. Análise de dados através de métodos de estatística multivariada: Uma Abordagem Aplicada. Belo Horizonte: Editora UFMG, 2005.

MONTEIRO, V. P.; PINHEIRO, J. C. Critério para implantação de tecnologias de suprimentos de água potável em municípios cearenses afetados pelo alto teor de sal. Revista de Economia e Sociologia Rural, Rio de Janeiro, v. 42, n. 2, p. 365-387, 2004.

Página 130 Caderno de Ciências Sociais Aplicadas, Vitória da Conquista/BA, vol. 15, n 26, ano 15, p. 111-131, jul/dez 2018. 
SECRETARIA DE SEGURANÇA PÚBLICA DO ESTADO DO RIO GRANDE DO SUL - SSP. Indicadores criminais 2016. Acesso em: 28 de out. 2017.

SPEARMAN, C. "General intelligence" objectively determined and measured. The American Journal of Psychology, Champaign, IL, v. 15, n. 2, p. 201-293, 1904.

THURSTONE, L. L. Multiple factor analysis. Psycological Review, Washington, DC, v. 38, n. 5, p. 406-427, 1931. 